\title{
LA CREACIÓN DE UNA ÉTICA CIENTT́FICA
}

Qué debemos entender exactamente por una ética científica es tal vez la cuestión más oscura en la filosofía del presente. La empresa de construir una estructura racional para la ética, es, hablando con Wittgenstein, "un asunto terrible, sencillamente terrible. Lo más que se puede hacer es balbucear cuando se habla de ello". ${ }^{1}$ Sin embargo, parece ser éste un asunto en el que todo el mundo quiere tomar parte, no solamente lógicos como Wittgenstein, sino también hombres de ciencia, desde físicos hasta antropólogos, y, por supuesto, filósofos de todas las convicciones: racionalistas y empiristas, realistas e idealistas, escépticos y absolutistas, positivistas, intuicionistas, emocionalistas y pragmatistas. En realidad, apenas habrá un campo, una actitud o un método en filosofía que no haya sido emplazado, de una manera u otra, como testigo en favor o en contra de una ciencia de la ética. A esta multitud de profesionales se ha añadido un coro de predicadores, políticos y personalidades públicas que, desde púlpitos y plataformas, en libros y panfletos, claman por una ciencia ética con el propósito, según dicen, "de restaurar el equilibrio entre la perfección tecnológica del hombre y su imperfección moral".

La escena contemporánea, pues, está agitada por una nueva pesquisa. La ciencia moral parece significar para nuestra época lo que la ciencia natural fué para el renacimiento. ¿Qué debe hacer el filósofo en esta situación?

En medio de toda la confusión presente una cosa es cierta: no existe todavía una ciencia ética. Si alguna vez ha de llegar a existir, debe, pues, ser creada. Esto suscita varios interrogantes. Primero, ¿es la creación de semejante ciencia un empeño que valga la pena? Segundo, ¿es siquiera posible esta ciencia? Tercero, ¿cómo podría ser puesta en obra y qué clase de ciencia tendría que ser? Cuarto, ¿cuáles serían su estructura y sus categorías? Quinto, ¿qué podría o debería llegar a realizar semejante ciencia? Vamos a discutir estas cuestiones en orden.

1. Preguntemos en primer lugar si la creación de una ética científica es una empresa que valga la pena. Supongamos por un momento que una ética semejante existiera ya, a saber: una estructura racional de proposiciones que, aplicada a los juicios en situaciones sociales particulares o individuales, nos dijera si tales juicios son o no moralmente correctos $y$, por lo tanto, si el camino indicado por ellos en la situación dada debiera ser el que hubiera de tomarse. ¿Sería valiosa semejante ciencia? Es obvio que ésta no es una pregunta científica, sino que pone en juego más bien el temperamento o la imaginación del hombre. Los tímidos retrocederán, los audaces avanzarán, los conservadores

1 C. H. Waddington, Science and Ethics, Londres, 1942; p. 7 .

[205] 
se pondrán inquietos, los radicales inspirados, los pesimistas no verán más que dificultades, los optimistas sólo promesas. ¿Valiosa?, dirán. |Vaya una pregunta! ¡Es la tarea de la época! No vale la pena si no tiene éxito. Una ciencia tal ordenaría nuestra caótica vida social e individual. No sólo esto; desde el punto de vista puramente filosófico y científico abriría nuevas regiones a la comprensión racional. Esta nueva empresa del espíritu promete aventuras de ideas y visiones descubridoras experimentadas, hasta ahora, en toda su plenitud, sólo por aquellos filósofos - los filósofos de la naturaleza- que inventaron los instrumentos de la ciencia natural y transformaron así nuestro mundo, de una multitud inconexa de aldeas aisladas y ciudades amuralladas, en una unidad conexa, entrelazada por teléfonos y cables, vías ferroviarias y carreteras, sendas aéreas y marítimas, ondas acústicas y luminosas. La filosofía natural ha cambiado la faz de la tierra a tal punto que Julio César y Colón no la reconocerían. Es igualmente cierto, infortunadamente, que Jesucrito la reconocería demasiado bien. Porque el paisaje interior en el que El se interesaba y donde esper6 establecer el Reino de Dios sigue siendo tan árido y estéril, tan caótico y anárquico, tan descuidado y falto de cultivo como en Su tiempo. Mientras la naturaleza física se ha rendido al espíritu inquisitivo del hombre y está abriendo para él el depósito de tesoros cada vez más ricos, la naturaleza interna del hombre es un yermo que éste nunca se ha tomado el trabajo de explorar con igual determinación. Aquí, en este paisaje interior al hombre y entre hombre y hombre, está todavía por hacerse todo el trabajo de cultivo, el trabajo de desmontar y arar, el trazado de carreteras y líneas de comunicación. Hay aquí un campo por labrar, una cosecha por recoger, tesoros por descubrir, recursos que movilizar y energías que liberar, las cuales bien pudieran dar ciento y raya a las de la naturaleza material. Cualquiera que tenga sentido de la naturaleza del hombre, de sus potencialidades ilimitadas, tal como se nos muestran en las parábolas de Jesús, en las obras de los genios morales y religiosos, desde Platón hasta Tomás de Aquino, desde Pico hasta Schweitzer, no puede sino asombrarse de las posibilidades que aguardan a la comprensión racional que el hombre puede ejercer de su propia naturaleza moral. Nos aguarda aquí una aventura de creación. Así como la aplicación del espíritu racional a la naturaleza exterior ha producido al creador del mundo moderno: la ciencia natural; de la misma manera, su aplicación a nuestra naturaleza interior producirá al creador del mundo futuro: la ciencia moral. Es ésta una empresa llena de valor para cualquiera que tenga ojos para ver y corazón para sentir. Quien carezca de ellos, por supuesto, no podrá tomar parte en la nueva aventura. Pero tampoco debe escuchársele, porque entonces la nueva empresa no se emprendería nunca. Lo que para el escéptico es locura, es deber para el pionero. El pionero no puede ser guiado por el derrotista, como tampoco puede serlo Miguel Āngel por un ciego o Casanova por un eunuco. La cuestión, pues, acerca de si la creación de la nueva ciencia vale la pena, no puede ser resuelta racionalmente. En lugar de preguntarnos si vale la pena, dejaremos 
establecido que podrá ser emprendida. sólo por aquellos que la consideren digna del esfuerzo.

¿No hay, pues, una norma que nos incite a emprender la aventura? ¿No es acaso la creación de una ciencia de la ética una empresa ética ella misma? De ser esto así, ¿qué norma debe guiarla? El establecimiento de la ciencia es, precisamente, un establecimiento de normas. ¿Qué norma debe, pues, guiarnos en el establecimiento de una norma? ¿Acaso aquello que habría de guiar la creación no es precisamente lo que tratamos de crear? ¿Cómo podemos decidir acerca de cuál sea nuestro deber en este caso si la norma de nuestro deber es precisamente aquello que es nuestro deber alcanzar? La creación de una ética universal -científica o no- ¿es éticamente posible?

2. He aquí nuestra segunda cuestión. ¿Cómo se relacionan entre sí el "deber" y el "poder" de crear la nueva ciencia? Si carecemos de una norma ética de acuerdo con la cual podamos decidir acerca de su creación, o bien no la crearemos, porque sólo podemos crear aquello que decidimos crear, o bien su creación no es un acto ético sino, digamos, psicológico. Lo que nos mueve a crear no es una norma ética universal -porque esto es precisamente aquello que queremos establecer- sino una especie de urgencia. Pero si es una urgencia lo que nos impele a establecer normas, ¿resulta necesario de algún modo el establecimiento de tales normas? ¿Cuál sería la función de una norma si no tuviera el poder de impelernos? Si lo que nos impele es una motivación psicológica, ¿por qué establecer normas universales? ¿No resultan entonces innecesarias? Si son realmente universales, no pueden ser psicológicamente eficaces, porque se encontrarían en una región que trasciende a la psique individual y no tienen, por ello, posibilidad alguna de influir en ella con suficiente fuerza para moverla. Por otra parte, si son psicológicamente eficaces, no pueden ser universales. De esta manera, nuestra averiguación no sólo parece ser no ética, sino incluso superflua, y una ciencia de la ética como instrumento eficaz de la vida moral sería a priori imposible.

Una argumentación similar a ésta ha sido propuesta recientemente por el Profesor Asher Moore. El Profesor Moore ${ }^{2}$ muestra que no puede darse un principio ético universalmente normativo en el sentido de que todos los hombres debieran seguirlo y sentir una obligación de seguirlo porque, por una parte, "el carácter normativo de un principio normativo depende de los hechos de la psicología humana” - porque, de no ser así, ¿cómo podría compelir a la conducta humana?-, mientras que, por la otra, "el carácter normativo de un principio normativo es independiente de los hechos de la psicología humana" -porque, ¿cómo podría, de otra manera, ser universal?-. Moore sostiene que estas dos proposiciones son contradictorias y que, por lo tanto, no es posible una ética normativa universal. La dirección de la filosofía moral en los últimos dos mil años ha estado, pues, equivocada.

2 “A Categorical Imperative?", Ethics, julio, 1953. 
Nuestra inquisición sigue, evidentemente, esta dirección equivocada. Si una ética científica fuera universal, entonces, de acuerdo con Moore, sería "psicológicamente ineficaz" y sería "simplemente otro hecho interesante acerca del modo de ser del mundo", pero no "una guía para una vida mejor". Si, por otra parte, una ética logra ser una tal guía, no podrá ser universal.

Es obvio que si una ética científica ha de ser al propio tiempo científica y ética, debe ser tanto universal como normativa. Supongamos por un momentc que la universalidad de una ciencia significa que ésta sea independiente de los hechos de la psicología humana. ¿Resultará por esta razón psicológicamente ineficaz? Puede decirse que la ley de gravitación es, en este sentido, independiente de los hechos de la psicología humana. Pero esto no quiere decir que sea psicológicamente ineficaz.

Aunque todo el mundo es libre de salir por la ventana, es de presumirse que el conocimiento de la ley de gravitación impelerá a cualquiera, por lo menos, a pensarlo dos veces antes de hacerlo. De la misma manera, aunque puede decirse que la proposición: " $2+2=4$ " es una ley universal e independiente de la psicología humana, es seguro que cualquiera, aun siendo libre para manejar sus asuntos de acuerdo con el principio de que dos y dos suman cinco, preferirá atenerse al de que dos y dos suman cuatro, puesto que todos lo hacen así, y de no decidirse en este sentido, se vería envuelto en dificultades considerables. Es justamente la universalidad de la ley lo que le impele a seguirla. Una ley contiene un elemento normativo justamente a causa de su universalidad. En este mismo sentido una ley de la ética puede ser universal y normativa. Puede ser tan fácil de desafiar como lo son las leyes de la gravitación o las matemáticas. Pero los resultados pudieran ser igualmente desastrosos. Los molinos de Dios podrán girar despacio, pero muelen muy fino.

Pero ni siquiera es verdad que las leyes de la ciencia, por ser universales, sean independientes de los hechos de la psicología humana. Dependen de estos hechos de dos maneras. Por una parte, tienen que ser creadas por mentes y voluntades humanas $y$, por otra, dependen totalmente de acciones humanas tales como leer relojes, tomar medidas, preparar experimentos y así sucesivamente. Esas leyes impelen al hombre a realizar siempre nuevas actividades de esta índole. Una ciencia, y la psique humana que se las ha con ella, forman parte de una y la misma totalidad, a saber, la actividad creadora del hombre, y ro pueden ser separadas la una de la otra. Es así como el carácter normativo de una norma científica depende de los hechos de la psicología humana $y$, al mismo tiempo, por ser universal, no depende de ellos. Estas dos proposiciones no son contradictorias, sino dialécticamente interdependientes.

Lo mismo tiene que valer para una ciencia de la ética. Debe ser creación de mentes y voluntades humanas y debe tener, al propio tiempo, una universalidad de aplicación que trascienda e incluya a tales voluntades e intelectos espoleándolos a una actividad perpetuamente renovada en la que se sigan, se apliquen, se prueben y se afinen estas leyes. 
Así, pues, la argumentación de Moore no ha probado que sea imposible una ética científica concebida como un sistema universalmente normativo de reglas. Más aún, no parece siquiera que sea posible prueba alguna de esa imposibilidad, toda vez que aquellos que quieren crear tal ciencia pueden siempre rechazar la prueba, ya sea por sus actos mismos o negando la lógica que ha servido para llegar a ella. La lógica dominante en una época se ha mostrado siempre como inadecuada para las tareas creadoras de esa misma época, y esto bien pudiera ser verdad incluso para la nuestra. La lógica actual es aquel instrumento mediante el cual tan sólo podemos balbucear, como decía Wittgenstein.

Aunque los lógicos, de Whitehead ${ }^{3}$ a Fitch, ${ }^{4}$ nos han hecho espléndidas promesas de una lógica de la ética, nada técnicamente importante se ha logrado por este lado, a pesar de medio siglo de desarrollo lógico concentrado y brillante. A juzgar por las actuaciones pasadas de los lógicos en el campo de la ética, particularmente de Russell, que ha admitido francamente su fracaso, ${ }^{5}$ parece que deberemos seguir adelante ateniéndonos solamente a nuestras fuerzas, tomando a cuenta de nuestros propios esfuerzos el injustificado derrotismo, las pretensiones igualmente injustificadas y las especiosas "pruebas" de los lógicos actuales. En este respecto, nuestra posición es semejante a la de los filósofos de la naturaleza, a quienes también se demostró, con la irrefutable lógica de la escolástica, que lo que hacían era imposible. "Ah, mi querido Kepler-escribía Galileo en su famosa carta-, cómo quisiera que pudiéramos reírnos de buena gana... al escuchar al profesor de filosofía de Pisa afanándose ante el Gran Duque con argumentos lógicos, como si fueran conjuros mágicos, para hechizar a los nuevos planetas y expulsarlos del cielo." Bien puede decirse que no tenemos la fortuna, que tenía Galileo, de poseer un telescopio y algunos satélites que mostrar, pero era tan difícil para Galileo convencer a sus contemporáneos del método empírico y matemático como es y será para nosotros convencer a nuestros contemporáneos de la posibilidad de una ciencia ética, si esta ciencia ha de constituir un punto de partida entera-

3 "Hemos de acabar con mi primer amor: la lógica simbólica. Cuando en un futuro lejano se haya ampliado hasta examinar esquemas de pensamiento dependientes de conexiones distintas de las de espacio, número y cantidad, cuando haya acontecido esta expansión, me parece que la lógica simbólica, es decir, el examen simbólico de esquemas de pensamiento con uso de variables reales, llegará a scr la fundamentación de la estćtica. A partir de esa etapa, procederá después a la conquista de la ética y la teología." "Remarks", Philosophical Review, 1937; p. 186.

4 "La única forma en que la humanidad puede desarrollar una ética y una filosofía conmensurables con su éxito en la fabricación de la bomba atómica cs hacer un uso pleno de la lógica simbólica para criticar y corregir los sistemas pasados de ética y filosofia y construir otros nuevos y mejores. Hacer menos que esto valdría tanto como tratar de investigar en fisica moderna usando la vieja aritmética romana que carecía del número cero." "Attribute and Class", Philosophic Thought in France and the United States, Marvin Farber, ed., Buffalo, 1950; p. 545 .

5 "The Elements of Ethics", Readings in Ethical Theory, W. Sellars and J. Hospers, ed., New York, 1952; p. 1, nota. 
mente nuevo. En caso de no serlo, la empresa tal vez no valga la pena. Así, por su naturaleza misma, la nueva ciencia habrá de transcurrir por un áspero camino.

3. Volvámonos, pues, a nuestra tercera cuestión y preguntemos cómo ha. brá de ponerse en obra la nueva ciencia y qué clase de ciencia deberá ser. De las muchas alternativas posibles seleccionaré dos de las principales, cada una de las cuales contiene muchas alternativas subalternas. La principal es la que se ofrece entre una ciencia natural y una ciencia no natural. Ambas son especies del genus ciencia; debemos, pues, aclarar la diferencia entre estas dos especies. Por ciencia entenderemos cualquier estructura sistemática de pensamiento o cualquier sistema lógico -siendo la lógica cualquier elaboración de la estructura del pensamiento- aplicable a un conjunto de hechos. Por "aplicable" entenderemos que la estructura sistemática del pensamiento determina en todos sus detalles la interrelación entre los hechos o acontecimientos.

Una ciencia, pues, tiene dos partes: una estructura formal de pensamiento y un contenido. Considerados aparte, ni una ni otro son, por sí mismos, la ciencia; sólo es tal su combinación. Así, ni los acontecimientos de la naturaleza física ni la red matemática que los une entre sí son la ciencia física, sino la combinaçión de unos y otra. La trama matemática de la física es sólo matemáticas, o, más bien, cierto campo selecto de las matemáticas; el contenido, o materia prima, de la física no es sino naturaleza o, más bien, ciertos acontecimientos especiales de la naturaleza. El conjunto total de reglas matemáticas y el conjunto total de acontecimientos naturales a que se aplican esas reglas son la ciencia de la física. ${ }^{\circ}$

El hecho de la aplicación produce una esfera intermedia entre la trama formal y el contenido al cual se aplica, que es precisamente la ciencia. Esta, a su vez, resulta también dividida en dos partes, ya sea que se subraye el aspecto formal o el material. Cuando se insiste en el aspecto formal se habla de la teoría de la ciencia; cuando se insiste en el aspecto material se habla de ciencia aplicada, práctica o experimental. La estructura formal aplicada a la ciencia se llama a menudo estructura formal aplicada, tal como en el caso de las matemáticas aplicadas, es decir, las matemáticas tal como son aplicadas en la física, en la ingeniería o en otros campos de la ciencia natural. Hablando estrictamente, pues, una ciencia consta de cuatro partes, a saber: la trama puramente formal, que es parte de la ciencia puramente formal, así las matemáticas; el mero contenido concreto, que es parte de lo dado realmente; y las formas intermedias: la teoría de la ciencia y la práctica de la ciencia.

Para poder ser aplicable, la estructura formal de la ciencia debe ser precisa, y lo suficientemente detallada para dar cuenta de la interrelación de los

6 Después de lo que hemos dicho anteriormente, el agente de la ciencia, el físico, debiera ser parte de la ciencia, y es parte dé ella en la forma idealizada del "observador". Empero, dejaremos este tercer requisito fuera de consideración. 
acontecimientos específicos y de su posición exacta dentro de la totalidad de la ciencia. La estructura formal no debe ser un conjunto general de principios inaplicable a los detalles. Por lo tanto, un sistema de pensamiento en términos de lenguaje cotidiano no es suficiente para desempeñar la función de constituyente sistemático de una ciencia. La filosofía como tal, por lo tanto, aun siendo una estructura sistemática de pensamiento, no es adecuada para servir como estructura formal de una ciencia. Carece del grado de elaboración indispensable para esa función. Empero, es la matriz de la ciencia, el suelo en el que ésta se desarrolla.

La ciencia natural nació de la filosofía natural. Pero no ha nacido todavía una ciencia moral a partir de la filosofía moral. Nuestro problema es el de averiguar si la ciencia moral ha de crecer por sus propias leyes a partir de la filosofía moral, o bien si aquello que nació de la filosofía natural, a saber, la ciencia natural, debe extenderse hasta el punto de valer por una ciencia moral.

La ciencia moral, o ética científica, si ha de ser una ciencia, debe tener los rasgos que hemos anotado para la ciencia; debe tener una estructura formal de pensamiento como la descrita y debe abarcar también ciertos fenómenos a los cuales sea aplicable esa estructura formal. Si afirmamos que la ciencia moral debe ser una ciencia naturalista, tendremos que reconocer que su estructura formal serían las matemáticas y que sus fenómenos serían acontecimientos pertenecientes a la naturaleza física.

Una vasta escuela de hombres de ciencia y de filósofos considera que la ciencia moral puede construirse como ciencia natural, esto es, aplicando las matemáticas o la lógica matemática a acontecimientos considerados como los de la naturaleza física. Naturalistas en este sentido lo son: Margenau, ${ }^{7}$ Northrop, ${ }^{8}$ Rueff, ${ }^{9}$ Waddington, ${ }^{10}$ Lundberg, ${ }^{11}$ Fitch ${ }^{12}$ y muchos otros, todos

7 "Ethical Science", The Scientific Monthly, noviembre, 1949; "Remarks on Ethical Science", The Nature of Concepts, Their Interrelation and Role in Social Structure, Stillwater, Oklahoma, 1950.

8 "Ethics and the Integration of Natural Knowledge", ibid.; The Logic of the Sciences and Humanities, New York, 1947; "The Physical Sciences, Philosophy and Human Values", Physical Science and Human Values, E. P. Wigner, ed., Princeton, N. J., 1947.

o From the Physical to the Social Sciences, Baltimore, 1929.

10 Science and Ethics, Londres, 1942.

11 Can Science Save Us?, New York, 1947.

12 Fitch parece creer que la lógica matemática del presente puede ser aplicada a la ética. Whitehead, por otra parte, cree que sólo puede serlo una nueva lógica simbólica no matemática. Por lo tanto, sólo Fitch, y no Whitehead, es un naturalista en el sentido antes indicado. Susanne Langer se encuentra entre los dos. "La lógica pura, de la cual son una rama las matemáticas puras, puede habérselas con cualquier tema que sea; no está limitada sólo a los conceptos y premisas que definen a las ciencias de la cantidad. Empero, las posibilidades de su aplicación a la ética, la estética, la historia, etc., están todavía completamente inexploradas. Nunca se ha emprendido sistemáticamente el análisis de conceptos tales como 'hecho histórico", 'valor', 'vida' y muchos otros. Nunca hemos tratado seriamente de encontrar los elementos conceptuales a partir de los cuales pudiera construirse una ciencia de la ética. No hemos hecho abstracciones que sean manejables, iluminadoras y limpias, vacías de significaciones ambiguas, capaces de ser muy elaboradas, de expresar 
los cuales creen que una ciencia de la ética puede construirse mediante el uso de los instrumentos de las ciencias naturales. De acuerdo con estos naturalistas, no hay nada en la ética que sea sui generis y que, por esta razón, no pueda ser expresado en términos de, o similares a los de, la ciencia natural. Estos abogados contemporáneos de una ética científica hecha a la imagen de las ciencias naturales se encuentran en una larga y distinguida tradición de racionalismo científico y empirismo, que se inicia con Descartes e incluye a Spinoza y Leibniz, Locke y Hume, todos los cuales escribieron con un propósito ético, implícito o explícito. El programa de Descartes, como lo ha mostrado Borkenau, era "moralidad matemática...; nada en el desarrollo del sistema de Descartes puede ser comprendido correctamente si no se comprende esto". ${ }^{13}$ Para Leibniz el cálculo diferencial no era sino una parte de un vastísimo cálculo de lógica universal aplicable a todas las ciencias y las humanidades, de tal manera que dos filósofos, en desacuerdo sobre un punto particular, en lugar de disputar infructuosamente no tendrían que hacer sino sacar sus lápices y ponerse a calcular. Spinoza aplicó el método geométrico a la totalidad de la ética en una Ethica ordine geometrico demonstrata. Locke escribió su Ensayo como prolegómenos a "un tema muy remoto de éste", a saber: la moralidad y la religión revelada, y mostró "que el conocimiento moral es tan capaz de verdadera certeza como las matemáticas". El título completo del tratado de Hume es Tratado de la Naturaleza Humana; Un intento de introducir el métcdo experimental de pensamiento en los asuntos morales. El mismo Berkeley no usó la epistemología sino como instrumento de la ética teológica.

Bien puede preguntarse por qué los grandes espíritus de la filosofía moderna y sus sucesores en la filosofía reciente y contemporánea no han sido capaces, hasta ahora, de construir la ciencia de la ética que consideraban como posible y necesaria. ¿¿Por qué este retraso entre el desarrollo de la filosofía natural y el de la filosofía moral, entre el estado de las ciencias naturales y el de las ciencias sociales, incluyendo a la ética, cuyo carácter filosófico y acientífico es obvio? Kecskemeti ha planteado claramente el problema en su interesante libro Meaning Communication and Value:

El retraso entre las ciencias naturales y las sociales puede interpretarse de dos maneras. Puede significar que la ciencia social llegará a tener tanto éxito como la física cuando aprendamos a aplicar los conceptos puramente causales, cuantitativos y no teleológicos a

estructuras intrincadas por sus innumerables posibilidades de combinación, en una palabra, términos descriptivos que formen un sistema cerrado singular, la estructura lógica de una teoría del valor." (The Practice of Philosophy, p. 207.) Lo más probable es que la nueva lógica simbólica no haga sino seguir a la nueva ciencia del valor. La técnica no precede a la concepción creadora, sino que la sigue. El modelo riemanniano de la relatividad hecho por Minkowski no precedió sino que sucedió a la teoría de Einstein; Descartes, Newton y Leibniz desarrollaron sus nuevas técnicas como medios de una nueva concepción filosófica, y no a la inversa.

13 Franz Borkenau, Der Übergang vom feudalen zum burgerlichen Weltbild. París, 1934, págs. 276 sigs. 
la conducta humana; puede significar también que la ciencia social se ha quedado rezagada porque los conceptos puramente causales, cuantitativos y no teleológicos, no pueden apresar la verdadera esencia de la conducta humana. Tenemos, por una parte, una promesa incumplida de progreso decisivo y, por la otra, una creencia no demostrada de que este progreso no puede obtenerse sobre la base del método propuesto.14

Lo más curioso de este debate entre naturalistas y no naturalistas es que, en realidad, los naturalistas resultan menos "científicos" que los no naturalistas.

Es el bando naturalista el que discute basándose en su fe en una analogía elemental no respaldada por evidencia táctica alguna, en tanto que los antinaturalistas se apoyan en la experiencia inmediata de fines y propósitos. De esta manera, ninguno de los dos aventaja al otro en su duro rigor empirista. De hecho, son los naturalistas los que parecen desempeñar el papel de utopistas de ojos rutilantes, en tanto que los antinaturalistas parecen más bien conservadores de ánimo estrecho que sólo creen en lo que actualmente ven y experimentan.15

Lo que los antinaturalistas ven y experimentan son, en realidad, los datos éticos específicos que no parecen adaptarse al molde naturalista y de los cuales, según creen muchos, puede mostrarse que no se adaptan a él por principio. En tanto que la ciencia natural se las tiene que haber con hechos de la naturaleza que pueden verificarse por la observación, la filosofía moral no tiene nada que hacer con semejantes hechos. Por el contrario, el tema central de la filosofía moral, a saber, el valor, parece ser una experiencia única y puramente privada. Esto significa, por cuanto respecta al método de la moral, que la lógica de clases, que presupone la intercambiabilidad de los ejemplos de los conceptos, es inaplicable al valor $y$, por lo que respecta al contenido de la ciencia moral, que no existe posibilidad alguna de verificación por una inspección pública.

Esto no significa, empero, que sea imposible una ciencia moral, puesto que la ciencia natural empírica y matemática no es sino una especie de la ciencia. Por el contrario, los antinaturalistas, que creen en esa ciencia, ${ }^{10}$ tienen tras de ellos una tradición igualmente vasta y distinguida que la de los naturalistas, tradición que empieza con Kant y encuentra su culminación moderna en G. E. Moore. Para Kant, la Metafísica de la Moral habría de guardar con la ética aplicada la misma relación que guarda la matemática pura con la matemática aplicada, ${ }^{17}$ de tal manera que la ética aplicada sería en el campo de la filosofía moral lo mismo que la matemática aplicada, o ciencia

14 Paul Kecskemeti, Meaning, Communication, and Value, Chicago, 1952; p. 217.

15 ibid.

16 Braithwaite, en su Moral Principels and Inductive Policies, Londres, 1950, llama a estos abogados antinaturalistas de la ciencia moral, "absolutistas".

17 Cf. Grundlegung zur Metaphysik der Sitten, Prólogo y Segunda Sección, primera nota. 
natural, ${ }^{18}$ en el campo de la filosofía natural. ${ }^{19}$ Los principios de esta ética sistemática o científica son desarrollados por Kant en oposición a los principios empíricos de la ciencia natural, aunque no a sus principios formales, ${ }^{20}$ a pesar de que la formalidad de la ética es de naturaleza distinta a la de las ciencias naturales. G. E. Moore considera sus Principia Ethica como "Prolegómenos a toda ética futura que pudiera pretender ser científica". ${ }^{21}$ "En otras palabras - nos dice-, he intentado descubrir los principios fundamentales del razonamiento ético." 22 El tema objeto de la ética científica, de acuerdo con Moore, no son las cosas particulares sino "todos los juicios universales que establecen una relación entre la 'bondad' y cualquier objeto".23 Se trata del "bien en general". ${ }^{44} \mathrm{La}$ ética es, en cuanto a la forma, una ciencia como la física o la química. ${ }^{25}$ De esta manera, la ética es, para Kant y Moore, un sistema formal de reglas que explicitan la naturaleza de la bondad "pura". Esta naturaleza radica, para Kant, en una buena voluntad; para Moore es indefinible, a pesar de que se pasó la vida entera explicándola de manera cada vez más cercana, y se aventuró, incluso, a definir ${ }^{26}$ lo intrínseco del valor, la mismidad en sí del "bien", ${ }^{27}$ y a llevar la exposición del bien mismo hasta dos proposiciones que no pueden unirse en una sola y convertirse así, presumiblemente, en una definición tan sólo por su contenido paradójico y aparentemente incompatible. Helas aquí: a) que el bien depende "sólo de la naturaleza inrtínseca que aquello que lo posee”. . y que, $b$ ) “aun siendo así, no es él mismo una propiedad intrínseca". ${ }^{28}$ Esta paradoja podría resolverse, y así determinarse la naturaleza del bien, dice Moore, si supiéramos en qué sentido las propiedades naturales intrínsecas describen a un objeto y las no naturales intrínsecas, o propiedades de valor, no lo describen. El término clave de la teoría, por lo tanto, es el término "descripción".29

Una ética no naturalista, si tiene las tres dimensiones de.la ciencia antes mencionadas, deberá ser mucho más que lo que, hoy por hoy, se llama Etica. Actualmente, la ética es un conjunto inconexo de teorías - Kant lo hubiera llamado una rapsodia- que se refieren sobre todo a ciertos estados psicológi-

18 Metaphysische Anfangsgruende der Naturwissenschaft, Prólogo.

19 Cf. Metaphysik der Sitten, Prólogo.

20 Cf. Metaphysik der Sitten, Introducción II.

21 Principia Ethica, p. IX.

22 ibid.

23 op. cit., p. XIII.

24 op. cit., p. 3.

25 op. cit., p. 4. La distinción que hace Moore entre ética y casuística corresponde a la que existe entre ciencia natural teórica y aplicada.

26 Philosophical Studies, p. 260.

27 Una cosa "es buena en sí misma o tiene valor intrínseco". Principia Ethica, VIII sigs.

28 Philosophical Studies, p. 273.

29 Philosophical Studies, p. 274; "A Reply to my Critics", The Philosophy of G. E. Moore, págs. 591 sigs. 
cos o fenomenológicos -satisfacción, felicidad, lealtad, simpatía, interés, adecuación, auto-realización, crecimiento, elección, aprobación, acuerdo-, todos los cuales no sólo se llaman "buenos", sino que se identifican con "bien", por la única razón de que se suponen presentes cuando algo es bueno. Este es el mismo estilo de pensamiento analógico usado por los alquimistas, quienes veían ciertas cualidades presentes cuando miraban el oro, pero no lograron nunca hacer oro. Sólo un estudio ulterior -el científico- pudo explicar por qué fracasaron: porque esas cualidades eran secundarias y no primarias. No tenían absolutamente nada que ver con la naturaleza intrínseca del oro. No de otra manera discutimos y enseñamos todavía las cualidades secundarias del "bien" para extrañarnos después de no poder "realizar el bien". Lo que en nuestros días se llama ética y se enseña como tal es una doctrina en gran parte alquimista, si no es, como dice Susanne Langer, ${ }^{30}$ una doctrina arcaica. Somos alquimistas de la moralidad, y el estado del mundo lo muestra con toda claridad. Una ética científica tendría que penetrar hasta las cualidades primarias del valor. Una vez encontradas tendría que desarrollar estas cualidades dentro de una estructura consistente que, en virtud de la universalidad del valor, tendría que ser una estructura formal. Esta estructura formal no sería ya una ética, sino que sería respecto de la ética lo que la estructura formal de las ciencias naturales - la matemática- es respecto de esas ciencias. En otras palabras, sería una ciencia formal que, al ser aplicada de cierta manera o a una cierta especie de fenómenos, produciría la ética, pero que, aplicada de otra manera o a una especie diferente de fenómenos, nos daría otra ciencia del valor, digamos, por ejemplo, la estética, y aplicada de una tercera manera o a una tercera especie de fenómenos nos daría, por ejemplo, la economía, y así sucesivamente. El valor, entonces, aparecería en estas diversas ciencias en formas tan diferentes como aparece el número en las distintas ciencias naturales -siempre el mismo Valor, pero siempre aplicado de manera diferente-. El valor ético sería diferente del estético, y el estético del económico; sin embargo, todos serían Valor y la interrelación entre las distintas formas del valor sería determinable con exactitud.

Necesitamos ahora un nombre especial para esta estructura formal, y le damos el nombre de axiología. La axiología es la estructura formal que guarda con la ética y con las ciencias sociales la misma relación que guardan las matemáticas con las ciencias naturales. La ética, pues, es axiología aplicada, y lo mismo son la estética, la economfa, la psicología, la sociología, la ciencia política y así sucesivamente. La creación de una ciencia de la ética, tal como lo han visto Susanne Langer y otros, trasciende el dominio de lo que en nuestros días se llama ética. Esta presupone más bien la creación de una teoría general del valor, de la que surjan "de un solo golpe" 31 las ciencias del valor, y que las relacione entre sí de la misma manera precisa como la física rela-

30 op. cit., p. 200.

31 Susanne Langer, op. cit., p. 209. 
ciona entre sí "la mecánica y la fisioquímica y la electrodinámica ... por un sistema elaborado". 32

Nuestro problema se convierte, pues, ahora, en el de si la axiología ha de ser una estructura matemática o matematicológica, o si ha de ser una estructura sui generis. En otras palabras, si la filosofía moral puede producir por su propio desarrollo autónomo un sistema formal sui generis, aplicable a los fenómenos morales y que nos aporte una técnica, tan exacta como sea necesario para poder manejar los conceptos de valor, análoga a la que la matemática moderna ha creado para el manejo de los conceptos de la ciencia natural. Quien se decida por la dirección naturalista negará que la filosofía moral contenga en sí el germen de semejante ciencia y vendrá a dar de nuevo en el bien desarrollado sistema originado por los filósofos de la naturaleza, Galileo y Newton, Descartes y Leibniz: las matemáticas. En otras palabras, tomará la filosofía natural como modelo para la ciencia moral. Esto podría significar, por supuesto, que la filosofía moral no tiene mayor utilidad que la de servir, por ejemplo, como objeto de análisis crítico. Aquel que, por su parte, decida tomar la dirección no naturalista, rechazará la autoridad de la ciencia natural en relación con los fenómenos morales y desarrollará la ciencia del valor autónomamente y de manera independiente de la ciencia natural, a partir de la filosofía moral.

Ambos métodos son igualmente difíciles y tienen sus ventajas y desventajas específicas. Los naturalistas tienen la ventaja de que pueden darse a la tarea de construir siguiendo las líneas conocidas de un modelo existente, pero tienen la desventaja de tener que intentar que a la fuerza entren los fenómenos de valor dentro de un armazón que puede ser inadecuado y que, incluso, pudiera bien contradecir su naturaleza misma. Este intento puede, por lo tanto, acabar en un fracaso, o no ser emprendido nunca, y los verdaderos lógicos positivos no culparán, por supuesto, a la estrechez de la lógica, ${ }^{33}$ sino a la vaguedad de la ética, convirtiendo su propio fracaso en virtud, a la manera de la zorra de las uvas. El antinaturalista, o, como bien podemos llamarle, el axiólogo, tiene la ventaja de poder analizar los fenómenos morales tal como son, y de poder adaptarles un sistema. Pero tiene la desventaja de que no existe tal sistema y de que ha de elaborarlo él solo con materiales desconocidos, de manera todavía no conocida y con vistas a propósitos desconocidos, de suerte que tiene que abrir brecha por territorios que no se encuentran en mapa alguno. Puede, pues, correr el riesgo de ser mal interpretado, o de ser totalmente incomprendido, como le pasó a Francis Bacon, cuyas observaciones, casi triviales para nuestros días, llevaron al Rey Jaime a comentar: "Es como la paz de Dios, sobrepasa todo entendimiento." El peligro más serio, sin embargo, que corre el axiólogo no es el de ser mal comprendido por otros, sino por

32 ibid. 231 sig.

33 Cf. P. F. Strawson, Introduction to Logical Theory, Londres, 1952; págs. 57 sig., 
sí mismo. Desde el momento en que no hay posibilidad de recurrir al testimonio de la verificación experimental, puede caer víctima de un auto-engaño mientras recoge diligentemente los materiales adecuados a los hechos de la naturaleza moral, midiendo y adaptando el sistema en torno a ellos como un sastre cuidaduso - pero menos avisado que los sastres imperiales del cuento de Hans Christian Andersen, quienes sabían bien lo que se hacían-, de tal manera que al final, cuando haga desfilar a su criatura por las calles, cualquier niño pueda ver que va desnuda.

A este respecto, pues, nuestra situación, aunque similar en muchos aspectos a la de los filósofos de la naturaleza en el origen de la ciencia natural, es completamente diferente. "Cuando el progreso decisivo en la física clásica se inició", dice Kecskemeti,

toda la evidencia acumulada del pasado apuntaba a la perfecta regularidad del movimiento de los cuerpos celestes, $y$ la pretensión de que estos movimientos podían explicarse por leyes matemáticas simples estaba plenamente respaldada por todos los conocimientos anteriores. En lo que se refiere a los hechos humanos, carecemos de tales conocimientos preexistentes. La única ventaja de los naturalistas consiste en que prometen, por lo menos, algo bien definido, una ciencia futura de la cual poseemos ya un modelo. Es sólo en este sentido que el naturalista puede invocar la experiencia pasada. En este punto los antinaturalistas padecen una desventaja. No pueden especificar el tipo de teoría científica que aspiran a desarrollar. Por otra parte, son los antinaturalistas los que pueden poner en orden el conocimiento existente y la experiencia acumulada, de tal manera que sirvan de apoyo a su posición. ${ }^{34}$

¿Cómo hemos de contestar, pues, a nuestra tercera cuestión? Es evidente que quien intente crear una ciencia de la ética deberá proceder en una u otra dirección, ya sea aplicando las ciencias naturales o creando un método a partir de la filosofía moral. En este último caso la decisión es particularmente difícil de justificar, porque a menos de haber empezado, por alguna concepción inicial de la naturaleza de la moralidad, a ver las líneas generales de un sistema ético no naturalista, se tendrá que insistir en el "no" - no habrá nada que decir sino: no, no, como el buen profesor de filosofía de Pisa. Por lo tanto, para poder tomar una decisión siquiera plausible en cierto grado, el axiólogo debe ser capaz de dar, por lo menos, un bosquejo de un sistema posible. De esta manera podría deshacerse de la desventaja principal de la posición axiológica, a saber: la carencia de alguna teoría científica hacia la cual apuntar.

Nuestra decisión, en cuanto a la cuestión tercera, es la axiología. Esto implica que no creemos en la fecundidad de la dirección naturalista. Para nosotros ésta es, más bien, un callejón sin salida. Por supuesto, ésta es una decisión subjetiva que no invalida en manera alguna cualquier intento de erigir una ética naturalista. No nos corresponde juzgar o rechazar posición alguna.

34 Kecskemeti, op. cit., págs. 217 sig. 
Nuestra tarea es la de construir, y la historia habrá de ponerlo todo a prueba. Empero, de acuerdo con el sistema que quiero trazar, la dirección naturalista está equivocada. La razón es que no puede dar cuenta, por lo que a mí se me alcanza $-\mathrm{y}$ en esto sigo, por supuesto, a Windelband y Rickert ${ }^{35}-$, del carácter único del valor intrínseco.

4. Hemos establecido, hasta el presente, que necesitamos un nuevo organon que habrá de ser respecto de la filosofía moral lo que son las matemáticas respecto de la filosofía natural, y que este nuevo organon no puede ser la matemática, o la lógica matemática, sino algo totalmente nuevo que debemos crear a partir de los materiales que nos aporta la filosofía moral. ¿Dónde comenzaremos, pues, dentro de la filosofía moral? Volvemos ahora a nuestro cuarto interrogante, relativo a las categorías y a la función de una ciencia del valor.

Thomas Hill, quien ha hecho el más amplio estudio que conozco de las teorías éticas, concluye que la teoría de G. E. Moore es aquella que, en su opinión, ofrece las mayores posibilidades de desarrollar una teoría moral aceptable en general. La encuentra superior, por una parte, por su "cualidad de interpretar coherentemente nuestra experiencia moral efectiva $y$, por otra parte, por su capacidad para expresar en sus propios términos las más valiosas intuiciones de otras teorías". ${ }^{36}$

Las dos características que, a mi modo de ver, debiéramos buscar en una ciencia de la ética son: un consistente dar razón de la experiencia moral y una interpretación consistente de las teorías morales conocidas. $\mathrm{Y}$ puesto que estas teorías morales dan cuenta de la experiencia moral, nuestra teoría debería dar cuenta de-las cuentas dadas sobre tal experiencia. Ahora bien, puesto que estas cuentas dadas constituyen unas ciertas éticas, la nuestra sería una meta-ética.

Concuerdo plenamente con el juicio de Hill y creo que la teoría de Moore debe ser el punto de partida de nuestra empresa. Pero éste es, necesariamente, un juicio subjetivo y seguirá siéndolo mientras la teoría que tengo en proyecto no haya sido ella misma construída y comprobada. Tal será el caso también de cualquier otra teoría moral que se proponga en nuestro tiempo. Abandonamos, pues, ahora, el suelo común que hasta aquí hemos tenido y no puedo por menos de rogar a quienes sigan mi argumentación que recuerden ( si es que puedo tomarme la misma libertad que se toma Moore al citar a Kant con ligeras alteraciones, de alterar a Hume convirtiéndolo un poco en Moore) que lo que voy a bosquejar "es una ciencia perfectamente nueva en la que nunca nadie había pensado, cuya idea misma era desconocida, y con res-

35 La palabra alemana Geisteswissenschaft que ellos emplean es la traducción de "ciencia moral". Fué introducida al idioma alemán en 1849 por el traductor de la Logic de Mill.

${ }^{36}$ Thomas Hill, Contemporary Ethical Theories, New York, 1950, p. 354. 
pecto a la cual nada de lo realizado hasta la fecha puede servirnos en lo más mínimo, salvo la sugestión hecha por Moore acerca del 'bien'. Con una diferencia, sin embargo, a saber: que en tanto que él no sospechó siquiera semejante ciencia formal, sino que condujo su nave a la playa, por mor de la seguridad, tomando tierra en el intuicionismo, para abandonarla ahí y dejarla que se pudriera, mi propósito es más bien el de dotarla de un piloto que mediante principios seguros de navegación, establecidos gracias a un conocimiento del globo, y provisto de una carta completa y un compás, pueda conducir la nave a puerto seguro. Si en una ciencia nueva, completamente aislada y única en su especie, empezáramos con el prejuicio de poder juzgar de las cosas por medio de un supuesto convcimiento adquirido previamente -a pesar de ser éste precisamente lo primero que habría de llamarse juicio-, no haríamos sino imaginar que vemos por todas partes lo ya conocido, porque las expresiones suenan de manera semejante. Empero todo aparecía radicalmente metamorfoseado, carente de sentido e ininteligible, porque tendríamos como fundamento nuestros propios pensamientos, convertidos en una segunda naturaleza por un largo hábito, en lugar de los del autor". ${ }^{37}$

Debo pedir al lector, por lo tanto, que se entregue plenamente al desarrollo de la argumentación. Creo que, a pesar de la necesaria subjetividad de la teoría propuesta, no le parecerá la travesía demasiado difícil. Por el contrario, espero que encuentre una navegación apacible, sin demasiadas sacudidas. De todos modos, aunque los detalles del sistema propuesto son únicos, los problemas que habremos de abordar serán aquellos mismos que encontrará cualquiera que haga el intento de crear una ética científica.

Erigir una ciencia a partir de la teoría intuicionista de Moore parece desde el primer momento una empresa destinada al fracaso, ya que el tenor del intuicionismo de Moore -que, por cierto, es de una especie muy particularse opone a ella. La única manera de proceder, por ende, será encontrar una estructura lógica que dé cuenta no sólo del contenido total de la teoría moral de Moore sino también de su método. La paradoja de este método es que, por una parte, y por lo menos en sus primeros escritos, sostiene que el "bien" es indefinible, mientras que, por la otra, se pasó la vida entera tratando de explicarlo, y nunca llegó a poner en claro qué relación guarda lo que él llama definición con esa explicación, exposición, o como quiera que llamase a lo que hacía con el "bien". El entendía por definición el análisis de un concepto, como lo dice claramente en su primer escrito sobre el asunto ${ }^{38}$ y aun en el último. ${ }^{30}$ Pero no aclara qué clase de concepto es aquel que no puede ser analizado, o en qué sentido pudiera esta clase de concepto llamarse en general todavía "concepto". Si algo que no puede ser analizado es un concepto, bien puede preguntarse si el concepto de un concepto inanalizable es él mismo

37 Prolegomena, Introduction.

38 Principia Ethica, págs. 6 sigs.

39 "Reply to my Critics", The Philosophy of G. E. Moore, Evanston, 1942; p. 665. 
inanalizable o no lo es. Como hemos de ver pronto, Moore sostiene la opinión de que su propio concepto del "bien" es tan inanalizable como el "bien" mismo.

De esta manera, un organon que hubiera de dar cuenta del método de Moore debe contener las reglas necesarias para poner en claro por lo menos tres puntos, a saber: qué es un concepto y cuál es la relación existente entre la exposición y la definición de un concepto. Para poder dar cuenta del contenido de la filosofía moral de Moore -la cual, como hemos visto, gira totalmente en torno al término "descripción"- nuestro organon tiene que dar razón de la naturaleza de la descripción y de su relación con la descripción de propiedades naturales intrínsecas y de propiedades intrínsecas no naturales. De esta manera, en conjunto, el organon que haya de dar cuenta de la teoría del valor de Moore debe contener, en un sistema lógico de pensamiento, los cuatro términos fundamentales de: concepto, definición, exposición y descripción.

Por añadidura, si ha de ser una teoría del valor, nuestro organon debe contener también las categorías usuales del valor, en particular las de valor extrínseco e intrínseco. En nuestros días se da razón de estas categorías en términos de teleología, considerándose a los valores extrínsecos como medios y a los intrínsecos como fines. Pero los términos "medio" y "fin" son ellos mismos tan vagos y ambiguos (como lo ha mostrado Broad, entre otros), en relación con el imperativo categórico de Kant, que se encuentran en una deplorable necesidad de ser, a su vez, analizados. ¿Qué es, en efecto, la teleología? ¿Existe algún sistema elaborado de pensamiento, en nuestro sentido, que pueda llamarse teleología? No hay tal. Explicar los valores extrínsecos e intrínsecos en términos de teleología es, por lo tanto, definir lo ignotum per ignotius. Pero -y esto es más serio- nunca se ha dado una razón de por qué los términos éticos fundamentales tenían que determinarse en términos teleológicos más bien que en otros términos cualesquiera. ¿Qué tiene que ver la teleología con la ética, hablando exacta y sistemáticamente? Esta pregunta no ha sido nunca contestada satisfactoriamente. Así, pues, si los términos "fin" y "medio" han de tener algún significado ético, la ciencia del valor no debe dar sólo razón de la importancia ética de la teleología sino producir, al mismo tiempo, un sistema teleológico consistente. Podemos considerar esto como un propósito secundario de la creación de una ética científica, propósito del mismo orden que los dos mencionados por Hill, a saber: dar razón de la experiencia moral y dar razón de las razones dadas de la misma experiencia, o sean las teorías morales. El propósito primario e inmediato de quien erige un sistema moral, en todo caso, es el de encontrar un sistema de pensamiento que dé razón de la descripción, exposición y definición de un concepto y del valor extrínseco e intrínseco en términos no teleológicos.

Estos cinco requisitos fundamentales pueden, sin embargo, reducirse a cuatro, porque una vez conocida la naturaleza exacta de la descripción, debe- 
remos, de acuerdo con Moore, conocer el valor intrínseco. Una definición del valor intrínseco debe, pues, encontrarse en términos de "descripción". Nos queda la definición del valor extrínseco y ésta pudiera encontrarse, o bien en términos de definición, o bien en términos de exposición. La tarea quedaría reducida entonces a encontrar un sistema lógico que contenga los términos clave de descripción, exposición y definición. ¿Dónde encontraremos este sistema?

Apuntaré ahora un procedimiento racional para encontrarlo, pero me apresuro a añadir que la creación de un nuevo sistema de pensamiento no procede racionalmente en este sentido. La exposición racional sigue, más bien, una intuición original. Gauss expresó ya esto diciendo: "El resultado ya lo tengo; ojalá supiera cómo llegar a él"; y Kant encontró en Hume los inicios de su propio sistema sólo después de haberlos establecido ya por sí mismo: "Porque tales principios generales, pero empero definidos, no pueden aprenderse fácilmente de hombres que los tienen sólo oscuramente en su espíritu. Uno debe dar primero con ellos por su propia reflexión y después los encuentra en todas partes, donde no hubiera uno podido encontrarlos al principio, porque los autores mismos no sabían que tales ideas se encontraban en la base de su observación." 40 Así, lo que voy a mostrar en la teoría de Moore tuve que ponerlo primero en ella -buen procedimiento kantiano-. Así como "el primer hombre (haya sido Tales o cualquiera otro) que demostró las propiedades del triángulo isósceles" tuvo que ponerlas primero él mismo en la figura, de la misma manera cualquiera que demuestre los principios ocultos en la teoría de otro debe ponerlos primero en ella. El verdadero método no consiste en inspeccionar una teoría, “y a partir de esto, de cualquier manera que fuese, leer en ella sus propiedades; sin hacer surgir lo que estaba necesariamente implicado en el concepto que él mismo había formado a priori... Si ha de conocer algo con una certeza a priori no deberá adscribir [a la teoría] absolutamente nada, salvo aquello que necesariamente se deriva de lo que él mismo ha puesto en ella de acuerdo con su concepto".41 Porque "la razón penetra sólo en aquello que ella misma produce según un plan propio". ${ }^{42}$ Así, la erección de un sistema presupone un acto creador de pensamiento a priori. Pero esto no puede ser descrito. En lugar de ello describiré un procedimiento empírico mediante el cual puede uno ser conducido al sistema formal que dé razón de la filosofía moral de Moore y pondré en claro que es enteramente ficticio. Un descubrimiento no puede ni podrá nunca acontecer así de una manera consciente.

Uno puede preguntarse si no podría encontrar, en el mismo Moore o en sus fuentes, el sistema lógico que diera razón de los tres términos en cuestión. Es paradójico, por supuesto, inquirir las fuentes de una intuición, y es toda-

\footnotetext{
40 Prolegomena, $\$ 3$.

41 Crítica de la Razón Pura, B XII.

42 B XIII.
} 
vía más paradójico querer encontrarlas en un sistema lógico. Pero si la filosofía de Moore es ciertamente una intuición, ¿por qué no usar el método de analizar intuiciones? ¿Por qué no investigar su mente inconsciente? Tal vez su intuicionismo no es sino una reacción contra algún sistema que hubiera absorbido en su juventud, pero que hubiera querido olvidar y cuya conexión con su propio pensamiento nunca hubiera llegado a ver con claridad. En ese caso, el sistema sería una especie de complejo intelectual; y Moore no habría sólo ignorado sus fuentes, sino que ni siquiera habría querido nunca conocerlas. Tal vez habría reaccionado con energía contra cualquier intento de explicar el mundo en términos de cualquier sistema. Habría insistido en el "sentido común"; y, específicamente, si alguien hubiera intentado dar razón de su filosofía en términos de algún sistema, no sólo se habría quedado perplejo, sino que incluso habría reaccionado violentamente contra tal intento. Pues bien, esto es justamente lo que él hizo.

Cualquiera que examine cuidadosamente la filosofía de Moore se sorprende de la emotividad de su acento. Pero ésta nunca alcanza intensidad mayor que la que puede encontrarse en su réplica (en la obra The Philosophy of G. E. Moore) a Abraham Edel. El ensayo de Edel lleva el título, absurdo desde el punto de vista de Moore, de "La estructura Lógica de la Teoría Etica de Moore". Esta concepción de la obra de Moore -en realidad extremadamente lúcida - es la única del volumen contra la cual Moore reacciona de manera positivamente descortés, si no es que con rudeza. El señor Edel, nos dice, "ha hecho una presentación fantásticamente deformada de mis concepciones éticas"; ${ }^{33}$ el ensayo de Edel es "sumamente oscuro y difícil". El mismo Moore se encuentra "totalmente incapacitado para encontrar una salida del laberinto construído por el señor Edel"; 44 la razón es que "el señor Edel se ha impuesto a sí mismo la tarea imposible de discutir la estructura lógica de algo que no tiene estructura lógica alguna". ${ }^{45}$ La fantástica deformación de los puntos de vista de Moore llevada a cabo por Edel radica "en la afirmación de que tıenen una estructura lógica particular, cuando de hecho carecen (en el sentido de Moore) de estructura lógica alguna". ${ }^{40} \mathrm{La}$ cuestión de si tienen una estructura lógica en algún sentido queda en la oscuridad, tanto más cuanto que Moore afirma que "no tienen estructura lógica". ¿Acaso siente él de manera oscura que pudieran tener una estructura lógica en algún sentido? ¿O son, como diría Kant, una mera rapsodia?

Habiendo confirmado sus sospechas de que en la filosofía de Moore pudiera haber algo más que la sola intuición, el analista de su psique creadora haría remontar ahora los procesos de pensamiento de Moore hasta sus fuentes. Encontraría que, según lo refiere el mismo Moore, los Principia Ethica se ini-

43 The Philosophy of G. E. Moore, p. 623.

44 ibid.

45 ibid.

46 ibid. 
ciaron en 1898, y que los años de 1896 a 1898 fueron "empleados en resolver las perplejidades suscitadas por las tres Críticas, los Prolegómenos y la Fundamentación de la Metafísica de las Costumbres, de Kant”. Lo que le inquietaba más particularmente era "qué podría haber querido decir Kant con la palabra razón".47

De este primer estudio de Kant surgieron las primeras publicaciones de Moore: "Libertad" y "La Naturaleza del Juicio", en la revista Mind, 1898 y 1899. En 1898 Moore empezó sus “primeras experiencias en la cátedra": ${ }^{48}$ un curso sobre la Etica de Kant, seguido inmediatamente por un curso de Etica, pura y simplemente. Después de su curso sobre Kant formuló esquemáticamente sus Principia Ethica. Fué, por decirlo así, una experiencia traumática, "un asunto extremadamente dificultoso" 49 y, por supuesto, que implicaba una frustración. "Me sentía de manera constante vagamente insatisfecho." 50

De esta manera, concluiría nuestro hipotético analista, el complejo contra la logicidad se origina en Kant. Toda la Etica de Moore es una reacción contra el sistema kantiano. Veamos, pues, si yace en el sistema kantiano la clave de nuestros tres términos: descripción, exposición y definición. Ciertamente, encontramos que la Lógica de Kant -que Kant había expuesto en la cátedra a lo largo de los 45 años de su vida académica, y que fué publicada en 1800 fué erigida en torno a ellos. ${ }^{51}$ Hasta aquí de nuestra pretensión ficticia de descubrir empíricamente la lógica de Kant en la filosofía moral de Moore.

Pasemos ahora a la construcción de nuestra ciencia de la ética. Estudiando la Lógica de Kant encontramos que, en verdad, sus términos clave son los de descripción, exposición y definición. Son éstas las etapas sucesivas de la clarificación de un concepto; y la clarificación del concepto es, nos dice Kant, "el asunto principal de la lógica".52 Así obtenemos la materia prima para nuestro organon, la estructura lógica que habíamos estado buscando, capaz de dar razón de los tres términos fundamentales. El problema de la clarificación, netamente establecido en la Lógica, tiene implicaciones para la filosofía trascendental de Kant -especialmente con relación a su concepción de lo analítico y lo sintético- que, aunque son importantes para la axiología, no pueden ser examinadas aquí. ${ }^{53}$ Baste decir que la lógica de Kant puede servir como un organon de pensamiento aplicable a la teoría ética.

\footnotetext{
47 The Philosophy of G. E. Moore, págs. 21 sigs.

48 op. cit., p. 23.

49 op. cit., p. 24.

50 ibid.

51 Sobre la diferencia entre esta Lógica y la lógica trascendental véase Walter Kinkel, Immanuel Kants Logik, Leipzig, 1920; págs. VII sigs.

52 Logik, Sect. VIII ("The Logical Perfection of Cognition According to Quality").

53 Para detalles, véanse los trabajos del autor: "The Analytic and the Synthetic as Categories of Inquiry", Perspectives, Departamento de Filosofía, Ohio State University, 1954, " "The Analytic, the Synthetic, and de Good: Kant and the Philosophy of G. E. Moore", Kantstudien, vol. 45, 1954.
} 
La tarea inmediata de nuestra construcción teórica es ahora la de encontrar una definición de "bien" que se preste a ser formulada en los términos de nuestro organon, a saber: descripción, exposición y definición de un concepto. Entre las muchas definiciones de "bien" existentes, hay una susceptible de adaptarse a nuestra manera, a saber: la que interpreta el "bien" como "bien de su especie". Interpretaremos esta definición de acuerdo con lo que Ewing ${ }^{54}$ llamaría su sentido lógico, de acuerdo con la relación entre el miembro y la clase. Una cosa es, pues, buena si posee todas las propiedades contenidas en su concepto de clase. Un buen ladrón, para usar el ejemplo de Ewing, es aquel que tiene todas las propiedades del concepto "ladrón". Es evidente que, en este punto, nuestra teoría trasciende al valor ético y tiene que habérselas con el valor en general o valor axiológico. Un buen ladrón, en sentido axiológico, es aquel que roba bien, tal y como el buen pulsador de lira de Aristóteles es aquel que pulsa bien la lira. El problema de si un buen ladrón o un buen pulsador de lira son además buenos o malos hombres es un asunto que, hablando sistemáticamente, no tiene nada que ver con la cualidad de su tunción específica. En otras palabras, hay un valor funcional y un valor personal y, sea de cada uno lo que fuere, no son el mismo. Sólo uno de ellos puede ser un valor ético, pero los dos tienen que ser, de alguna manera, valores axiológicos. La axiología debe contener reglas de aplicación que pongan en claro qué clase especial de valor axiológico es la ética; pero también qué clases especiales del mismo son la estética, la sociología, la psicología y otras ciencias del valor. La bondad inherente al realizar una cierta función y ser, por ello, miembro de una cierta clase social -ladrones, tocadores de lira, etcétera-, parece ser tema de la sociología. La ética y la sociología, así como todas las demás ciencias del valor, son, pues, como se ha dicho antes, axiología aplicada, y la axiología es la estructura formal de la ética, la sociología, etc., tal y como la física no es sino matemática aplicada y la matemática es la estructura formal de la física y de las otras ciencias naturales.

Después de haber definido el "bien" en estos términos axiológicos generales, a saber: como aquel predicado que indica que el sujeto tiene todas las propiedades contenidas en su concepto de clase, hemos eslabonado "bien" con "concepto" y hemos aplicado, así, nuestro organon al valor -habiéndonos topado en ese proceso no sólo con el valor ético, sino también con el valor axiológico en general.

Nuestro próximo paso debe ser el aplicar nuestros tres términos fundamentales, definición, exposición y descripción, a la relación entre el miembro y la clase. A este propósito debemos construir tres especies distintas de clases, a saber: definitoria, expositiva y descriptiva. La clase definitoria es la de la lógica del presente, a saber: aquella cuyos miembros tienen las propiedades de la definición del concepto. La definición, en este sentido, se llama a veces 
comprensión o connotación convencional de la clase o del concepto. La clase expositiva es aquella cuyos miembros poseen las propiedades de la exposición del concepto. En tanto que la definición tiene dos términos: gentus y differentia, la exposición tiene muchos; determinar cuántos son y cómo se relacionan entre sí es una de las tareas de la axiología. La exposición de un concepto es similar a la llamada comprensión subjetiva, a saber: la suma total de atributos presentes en el espíritu de la persona que emplea el término. La clase descriptiva, finalmente, es aquella cuyos miembros poseen todas las propiedades de la descripción del concepto. Determinar la diferencia entre la exposición y la descripción del concepto es, nuevamente, tarea de la axiología. No hay nada en la lógica del presente que corresponda a la descripción en este sentido. La diferencia entre descripción y exposición radica en el hecho de que la exposición contiene un número finito de miembros, en tanto que la descripción contiene, o bien un número infinito de ellos, o bien un número finito con significación infinita. De esto se sigue que el número de miembros de la clase descriptiva está límitado a un solo individuo para el cual pueden siempre encontrarse nuevas propiedades. Por otra parte, si un concepto se refiere a más de un individuo, deben haberse abstraído un cierto número de propiedades que posean en común no importa cuántas, a condición de que sean en número finito. De aquí se sigue una definición de la unicidad axiológica: cualquier cosa que posea un número infinito de propiedades es única. La descripción es, pues, la comprensión de un ser único.

Habiendo construído así tres especies diferentes de clases y tres diferentes especies correspondientes de miembros de clase, aplicaremos estas tres especies a la definición de "bien" establecida anteriormente y obtendremos tres clases de "bien", a saber: el bien de los miembros de la clase definitoria; como poseedores de todas las propiedades de la definición; el bien de los miembros de la clase expositiva, como poseedores de las propiedades de la exposición, $y$, finalmente, el bien de los miembros de la clase descriptiva, como poseedores de todas las propiedades de la descripción. Examinando estas tres especies de bienes o valores, encontramos que la primera especie, la definitoria, o valor lógico, no es un valor axiológico. En efecto, si una cosa no tiene todas las propiedades de su definición, siendo así que la definición da el mínimo de las propiedades de la clase, la cosa no es, en absoluto, miembro de la clase currespondiente, ni puede, por lo tanto, ser un miembro bueno o malo de la misma, o ser buena o mala en su especie, porque con cualquier pérdida de propiedades no sólo pierde su bondad sino también su existencia lógica como miembro de la clase. Cuando $\mathrm{x}$ es un $\mathrm{C}$ sólo a condición de que $\mathrm{x}$ posea todas las propiedades de $\mathrm{C}$, resulta que $\mathrm{x}$ no será un $\mathrm{C}$ si carece de cualquiera de las propiedades de C. A los miembros de la clase definitoria o lógica, los llamaremos cosas definitorias, lógicas o sistémicas. Sus definiciones son, por supuesto, lo que Kant llama definiciones sintéticas, las cuales dan, consigo mismas, e] 
concepto de la cosa. A ésta pertenecen los círculos, triángulos, electrones, números y todos los esquemas de cualquier cosa; todos están excluídos de valoración alguna. No pueden darse círculos geométricos buenos o malos sino sólo círculos o no círculos.

Los miembros de la clase expositiva, por otro lado, pueden tener algunas de las propiedades expositivas de más o de menos y seguir siendo miembros de la clase. La razón de esto radica, como ha mostrado Kant, en que tales cosas son empíricas y sus conceptos no surgen por definición sino por abstracción. Una cosa empírica que tenga una exposición puede tener también una definición, pero ésta no será la definición sintética de las cosas no empíricas, sino la definición analítica, que es sólo la expresión mínima de la exposición. Vemos así, que el proceso kantiano de la clarificación se refiere sólo a cosas o estados empíricos. Esto nos lleva a un resultado axiológico importante. El argumento de Moore, si ha de conducir a algo, debe llevarnos a una definición analítica, y puesto que el nuestro parte de una definición sintética, resulta evidente que aquello de que se ocupa Moore es la experiencia del bien, en tanto que lo que nos preocupa a nosotros es el predicado "bien".

De manera análoga a las cosas no empíricas, puede decirse que las cosas empíricas no son miembros de su clase cuando carecen de alguna de sus propiedades definitorias. Así, para usar el ejemplo de Moore, si la definición de un caballo es "cuadrúpedo ungulado del género equino", no puede ser un caballo cualquier cosa que no sea un cuadrúpedo ungulado del género equino, aunque tuviera alguna de las propiedades expositivas del caballo, tales como crin, cola y una detadura. Por otra parte, puede existir una criatura que carezca de crin, de cola o de dientes, y que, sin embargo, sea un caballo. Sería, ciertamente, un caballo bastante malo. Un buen caballo tiene todas las propiedades expositivas. La clase expositiva, por lo tanto, nos conduce a la evaluación, aunque no a la estimación de la cosa como tal o en sí misma -este caballo particular, Roger, Browny o Pegaso-, sino a la estimación de la cosa como miembro de la clase. A esta especie de valor la llamaremos valor extrínseco.

Finalmente, para ser un bien de su especie, una cosa puede satisfacer plenamente su concepto descriptivo, es decir, puede poseer la totalidad infinita de las propiedades contenidas en él. Esta especie de valor es el valor intrínseco. La aplicación de esta definición del valor intrínseco a la filosofía moral de Moore resuelve sus paradojas y efectúa así sobre ella justamente la operación que una nueva ciencia debe realizar sobre sus antecedentes oscuros, a saber: convertir la intuición en racionalidad, la profundidad en simplicidad. Para hablar con Husserl,

la profundidad es síntoma de un caos que la ciencia verdadera debe tratar de resolver en un cosmos... La verdadera ciencia, en la medida en que ha llegado a ser doctrina definible, no conoce profundidad alguna... Dar nueva forma y transformar los oscuros tan- 
teos de la profundidad en proposiciones inequívocas y racionales es el acto esencial en la constitución metódica de una nueva ciencia. ${ }^{55}$

La aplicación fecunda de la axiología a las idas y venidas de la argumentación de Moore es, en sí misma, una prueba de su validez, por la que debe pasar cualquier otra axiología. Explicar, adicionalmente, la dirección de la misma filosofía de Moore a lo largo de la jerarquía kantiana de la clarificación, desde la descripción y la exposición hasta la definición -nunca definitivamente obtenida- del valor intrínseco, es una realización ulterior que cualquier axiología debe llevar a cabo..$^{56}$

De esta manera, las tres categorías de nuestro organon, definición, exposición y descripción, nos han conducido hasta tres especies de valor: valor sistemático, valor extrínseco y valor intrínseco. Tanto el valor extrínsecō como el valor intrínseco son valores axiológicos, en tanto que el sistemático es no axiológico. De esta manera no sólo hemos desarrollado los dos valores fundamentales a partir del organon kantiano, sino que en el proceso hemos derivado una tercera especie caracterizada por su carácter no-estimativo. El no-valor es diferente del contravalor. Este último es un valor axiológico y es simplemente la maldad contraria a la bondad. La maldad a su vez puede ser extrínseca o intrínseca. Si una cosa que realiza plenamente su exposición es extrínsecamente buena, una cosa que no realice plenamente su exposición es extrínsecamente mala. Si una cosa que realiza plenamente su descripción es intrínsecamente buena, entonces una cosa que no realice plenamente su descripción es intrínsecamente mala. Resulta claramente visible que una cosa puede no realizar plenamente su exposición y ser, sin embargo, miembro de su clase, pero es más difícil ver de qué manera una cosa puede no realizar su descripción y, sin embargo, seguir siendo miembro de su clase. Porque si la clase tiene sólo un miembro, y este miembro tiene todas las propiedades infinitas de la descripción; si, en otras palabras, es lo que es, çno se sigue necesariamente que al carecer de cualquiera de esas propiedades se convierta en otra cosa con otro concepto descripcional? Además, ¿qué puede significar no realizar una infinidad de propiedades? ¿Acaso en una infinitud no son el todo y la parte de la misma magnitud? Todas estas cuestiones deben y pueden ser contestadas por la axiología. Hay, por ejemplo, ciertas cosas que contienen en sí mismas su propia descripción, a saber: todas las "cosas pensantes", para usar el término cartesiano del yo. De esta manera, una cosa puede no elevarse efectivamente hasta la descripción de sí misma por sí misma; esta descripción es entonces todavía completa, pero no corresponde a la actualidad de la cosa. Esto implica, por supuesto, un análisis detallado del yo y de su relación con la auto-conciencia, por una parte, y con la presencia actual, por

55 "Philosophie als strenge Wissenschaft."

56 Para detalles, véase "The Analytic, the Synthetic, and the Good: Kant and the Paradoxes of G. E. Moore". 
la otra. ${ }^{57}$ Además, ¿̨cómo puede una infinitud carecer de alguna de sus partes o ser incompleta? La solución radica en no considerar la infinitud de la descripción aritméticamente, como un número infinito de términos, sino geométricamente, como una Gestalt. Todo el aparato de la teoría de la Forma: organización, clausura, Prägnanz, etc., está a nuestra disposición. ${ }^{58} \mathrm{El}$ concepto descriptivo de una cosa, entonces, no es sino Gestalt..$^{59}$

Las tres categorías de la axiología, el valor extrínseco y el intrínseco y el valor sistemático, son categorías del lenguaje del valor, esto es, el sistema formal de la axiología. Deben ser desarrolladas de dos maneras: dentro del sistema mismo de la axiología y en sus aplicaciones a las situaciones concretas de la realidad del valor.

Como elementos de la ciencia formal de la axiología, estas categorías aparecen en proposiciones típicas que tienen ciertos sujetos y ciertos predicados conectados con ciertas cópulas. Los sujetos, predicados y cópulas pueden, a su vez, ser lógicos o axiológicos. Así, un sujeto no-empírico en el sentido definido, a saber: aquel cuyo concepto surge por definición sintética, es siempre lógico más bien que axiológico; un sujeto empírico, por otra parte, puede ser axiológico. De la misma manera hay predicados y cópulas que son lógicos y otros que son axiológicos. El predicado es axiológico si es una de las palabras de valor, tales como "bueno", "regular", "malo" o "pésimo" (no good). Estos son los términos básicos de valor. "Bien" significa que el sujeto realiza su exposición -nos desentenderemos por ahora del valor descriptivo o intrínseco y nos limitaremos al valor extrínseco. "Regular" significa que la realiza en parte. "Malo" que no la realiza parcialmente. $Y$ "pésimo" que no la realiza. En otras paiabras, cuando la cosa tiene todas sus propiedades expositivas, se la llama "buena"; cuando tiene algunas de ellas, se la llama "regular"; cuando no tiene algunas, se la llama "mala"; y cuando no tiene ninguna, se la llama "pésima" (no good). "Bueno", "regular", "malo" y "pésimo" son los cuatro términos axiológicos básicos; son, al mismo tiempo, lo que llamaremos los cuantificadores y cualificadores axiológicos de la proposición. Así como algunos cuantificadores y cualificadores lógicos se encuentran implícitamente en otros términos -el cuantificador universal y cualificador negativo en la palabra "no", el cualificador positivo en el verbo, el cuantificador particular a menudo en el sujeto-, de la misma manera el cuantificador y cualificador axiológicos están siempre contenidos en el predicado axiológico. "Bueno" es universal y positivo, "regular" particular y positivo, "malo" particular y negativo y "pésimo" (no good) universal y negativo. Obtenemos así un cuadro axiológico de

57 Para un inicio de esto cf. "A Logical Definition of Value" del autor; Journal of Philosophy, 1951, págs. 415 sigs.

58 Cf. Risieri Frondizi, The Nature of the Self, 1953; págs. 148 sigs. También, de Wolfgang Köhler, The Place of Value in a World of Facts, 1938.

59 Esto es algo muy diferente de cualquier cosa que pudiera derivarse de la lógica de nuestro tiempo, por ejemplo de la de Carnap. En general, parece más prudente para el axiólogo dejar en paz, de acuerdo con Rickert, a la lógica conceptual o nomotética. 
oposiciones en el que "bueno" y "pésimo" son contrarios, "bueno" y "malo" -y "pésimo" y "regular" contradictorios, "bueno" y "regular" y "pésimo" y "malo" sub-alternos, y "regular" y "malo" sub-contrarios.

Mientras en un caso particular la clase definitoria puede existir sin la clase expositiva, esta última no puede existir sin la primera. La clasificación lógica y la axiológica y, por lo tanto, la cuantificación y la cualificación, deben ir de la mano. Cualquier proposición axiológica debe ser analizada tanto lógica como axiológicamente. Así, todos los $x$ son buenos es, tanto lógica como axiológicamente, universal y positiva. Todos los $x$ son malos es, lógicamente, universal y positiva $y$, axiológicamente, particular y negativa. Algunos $x$ son buenos es, lógicamente, particular y positiva $y$, axiológicamente, universal y positiva, $y$ así sucesivamente.

Mientras "bueno", "regular", "malo" y "pésimo" (no good) son los predicados básicos de valor, hay un gran número de expresiones equivalentes que se les relacionan, como los cuantificadores lingüísticos - "pocos", "solamente", etcétera - se relacionan con los cuatro cuantificadores básicos. Estos cuantificadores axiológicos lingüísticos son: "excelente", "perfecto", "magnífico", etcétera, para bueno; "así-asi", "no del todo mal", "pasable", etc., para regular; "pobre", "inferior", "deficiente", etc., para malo; "podrido", "mugroso", "miserable", etc., para pésimo (no good). Se usan a veces, como cuantificadores axiológicos, expresiones idénticas o similares a las de los cuantificadores lógicos, como por ejemplo: "muy" en "muy hombre", o bien "todo" en "toda una fortuna", o "gran" en "gran cosa". A veces se usan también cuantificadores axiológicos como cuantificadores lógicos: "podrido de dinero".

Aparte de los predicados axiológicos puros que acabamos de discutir hay también predicados axiológicos aplicados. Estos son predicados que surgen de la aplicación de los predicados axiológicos puros a ciertos campos, por ejemplo, la ética o la estética. Como veremos, la ética no es sino la aplicación del valor intrínseco a los seres humanos. La ética es, entonces, la ciencia de la relación existente entre la descripción de una persona o Gestalt, su conciencia de esta Gestalt y su yo actual. Una persona cuya actualidad corresponda con su propia descripción de sí mismo, ya sea ésta expresada en acción o no, es lo que llamamos un hombre moralmente bueno. Aquí "bueno" no es un término axiológico, sino ético; es una palabra de valor, pero no pertenece a la axiología; pertenece a la axiología aplicada. Es la aplicación del "bueno" axiológico -realización de un concepto descriptivo- a una persona. La confusión entre el "bien" ético y el axiológico ha sido la maldición de la ética en los últimos dos mil años y ha impedido la aparición de una teoría general del valor.

Otro predicado axiológico es el de "sincero". Una persona moralmente buena, en el sentido discutido, y que expresa esta bondad en sus acciones, es sincera. "Sincero" es, pues, un caso específico del "bien” moral, el cual a 
su vez es una aplicación del bien axiológico a un campo especial, a saber: la persona humana. Así, la aplicación de la axiología a un campo especial da nacimiento a una ciencia específica de axiología aplicada, y el análisis de esta aplicación elabora la ciencia como la relación que guardan entre sí ciertos términos, todos los cuales son predicados de valor. Todos los predicados que no son axiológicos son lógicos.

Las cópulas pueden ser también lógicas o axiológicas. La cópula lógica es "es", la axiológica es "debe". "Debe" pertenece a una tercera especie de términos axiológicos -además de los sujetos y predicados-, a saber: las relaciones axiológicas. Son relaciones axiológicas: "mejor que", "bueno para", "es bueno que", y otras por el estilo. "Debe" es una combinación de "mejor que" y, o bien, "bueno para", o "es bueno que". $\mathrm{El}$ análisis de todas estas relaciones es otra tarea de la axiología. $x$ es mejor $C$ que $z$ significa que $x$ tiene más propiedades de $\mathrm{C}$ que $\mathrm{z}$ y que es, por lo tanto, más $\mathrm{C}$ que z. "Mejor que" relaciona dos miembros de la misma clase empírica, el primero de los cuales posee más propiedades de la clase expositiva que el segundo. "Peor que" es la relación axiológica inversa, la que se da entre $\mathrm{z}$ y $\mathrm{x}$. $x$ es bueno para $z$ significa que $\mathrm{x}$ y $\mathrm{z}$ están en clases diferentes y que $\mathrm{x}$ es parte de la exposición de la clase de z. El heno es bueno para los caballos significa que parte de la exposición de "caballo" dice que el conducto digestivo de los caballos tiene una afinidad con el heno. $x$ es malo para $z$ significa que $\mathrm{x}$ es contrario a alguna parte de la exposición de z. El arsénico no es bueno para los caballos significa que el arsénico es contrario a algo que es bueno para los caballos. Es bueno que $x R z$ significa que la relación $\mathrm{R}$ es parte de la exposición de uno o todos sus términos. Es bueno que Juan lea Ivanhoe significa que leer Ivanhoe es bueno para Juan, o que pertenece a la naturaleza o exposición de Juan leer Ivanhoe. Así, "mejor" y "peor" son relaciones axiológicas entre miembros de la misma clase; "bueno para" y "malo para" son relaciones axiológicas entre miembros de clases diferentes; $y$ "es bueno que" y "es malo que" son relaciones axiológicas para relaciones. Lo que falta, pues, es la relación axiológica entre un miembro y su clase, y esta relación es la cópula axiológica "debe".

"Debe" no relaciona dos cosas, tales como " $\mathrm{x}$ " $\mathrm{y}$ " $\mathrm{z}$ ". Decir que $\mathrm{x}$ debe ser $z$ carece de sentido puesto que significa que una cosa debe ser otra cosa. "Debe" relaciona más bien cosas con conceptos. $x$ debiera ser un $C$ significa que, o bien $\mathrm{x}$ es un $\mathrm{C}$ y que es o no es deficiente a este respecto, o significa que $\mathrm{x}$ no es un $\mathrm{C}$, sino, digamos, un $\mathrm{B}$ y que sería "mejor para" $\mathrm{x}$ ser un $\mathrm{C}$. "Debe", pues, es equivalente a "mejor para" o "es mejor que". $x$ debe ser bueno es equivalente a es mejor para $x$ ser bueno, y $x$ debe ser un $C$ es equivalente a es mejor para $x$ ser un $C .{ }^{60}$ Así, lo que $\mathrm{x}$ debe ser es siempre mejor que lo que $x$ es. A la inversa, lo que $x$ no debe ser es siempre peor que lo que $\mathrm{x}$ es.

60 Cf. la forma "had better", en " $x$ had better be $C$ " en inglés, que refuerza el sentido de "ought" (debe). 
"Debe" relaciona, pues, el ser peor de una cosa con su ser mejor, y "no debe" relaciona el ser mejor de una cosa con su ser peor. Luego, lo que $\mathrm{x}$ es, es siempre peor que lo que $\mathrm{x}$ debería ser, pero mejor que lo que $\mathrm{x}$ no debe ser. El otro constituyente de "debe" es "bueno para", o "es bueno que". Si x debe ser $C$, esto significa o bien que $\mathrm{x}$ encontrará lo que es mejor para él, no en su propia clase, digamos $B$, sino en otra, o bien que el ser $\mathrm{x}$ en $\mathrm{C}$ cumple el concepto de $x$. El primero puede llamarse un "debe" sintético, y el segundo analítico. En ningún caso, pues, puede el "deber" relacionar cosas, sino siempre cosas y conceptos. Esta prohibición del uso de la cópula axiológica corresponde a la prohibición del uso de la cópula lógica en la teoría de los tipos.

Además de los predicados de relaciones axiológicas, hay términos axiológicos que son combinaciones de predicados y relaciones, tales como, por ejemplo, "el mejor" y "el peor". $x$ es el mejor $C$ significa que $\mathrm{x}$ es el único y exclusivo $C$ que posee el máximo de propiedades exposicionales de C. $x$ es el peor $C$ significa que $\mathrm{x}$ es el único $\mathrm{C}$ que tiene el mínimo de propiedades expositivas de $\mathrm{C}$-lo cual no significa que $\mathrm{x}$ sea pésimo. $\mathrm{El}$ peor $\mathrm{C}$ puede ser bastante bueno.

El análisis de "debe" a diferencia de "es" nos conduce a la teoría de los valores de verdad de las proposiciones axiológicas. Debe hacerse una distinción entre juicio y proposición -nuevamente en sentido kantiano- en la que la proposición es la afirmación de algo que en el juicio es todavía problemático. La diferencia entre proposición y juicio radica, pues, en la modalidad del pensamiento. ${ }^{61}$ Toda proposición axiológica tiene uno o varios bosquejos subyacentes de pensamiento que no son expresados en la proposición misma, y cuyo número depende del número de términos de la proposición que sean axiológicos más bien que lógicos.

Para poder ser axiológico, el sujeto debe ser empírico. Debe, por lo tanto, ser un término que se refiera a algo exterior a la proposición y que puede o no existir en la realidad actual. Esta realidad es el trasfondo sobre el cual ha de juzgarse a la proposición, por cuanto concierne a su sujeto. En las proposiciones lógicas con sujetos empíricos -donde el predicado y la cópula son también lógicos más bien que axiológicos- la proposición entera se mide - como verdadera o falsa - por este trasfondo al que, en este caso, se refiere también el predicado; y la comparación entre los hechos del trasfondo y el contenido de la proposición determina la verdad o la falsedad de esta última.

Si el predicado es axiológico, esta determinación simple de la verdad y de la falsedad fracasa, porque los términos de valor "bueno", "malo" y todos los demás, tienen significaciones que sólo pueden ser determinadas consultando su definición axiológica. Su "trasfondo" es la estructura de la axiología. Son términos sistemáticos, ${ }_{2}^{62} \mathrm{y}$ cualquier proposición que los contenga debe ser

61 Logik, \$30; Crítica de la Razón Pura, B 100 sig.

62 Por esta razón no pueden ser sujetos de proposiciones axiolbgicas. El bien es bueno no significa nada, si se designa con ello al bien axiológico. Esto quiere decir que nuestra 
juzgada de acuerdo con las reglas de la axiología. Tales proposiciones, por lo tanto, no pueden ser verdaderas o falsas sino, como otras proposiciones sistemáticas, solamente válidas o inválidas - esto es, válidas o inválidas en términos de la axiología como ciencia formal-. Si, por otra parte, el predicado de valor no pertenece a la axiología pura sino a la aplicada, por ejemplo, Juan es sincero, entonces son pertinentes tanto la verdad como la validez en el sentido axiológico.

Tanto como el sujeto y el predicado, la cópula "debe" tiene un trasfondo; y éste se encuentra, por decirlo así, entre los del sujeto y el predicado. E] trasfondo del sujeto es la realidad empírica, el del predicado axiológico es el sistema de la axiología. El trasfondo de "debe" no es, ni la realidad empírica, ni un sistema formal de pensamiento, sino una síntesis de los dos: el pensamiento como realidad empírica. Es el juicio que se encuentra en el espíritu de la persona que expresa la proposición. En estos juicios, que no son expresados y que son, por lo tanto, puro tema de pensamiento, la modalidad -asertórica, problemática o negativa - es de importancia primaria tanto para ellos como para la significación de la proposición de deber. Cuando digo, por ejemplo, Juan debe ir a la escuela, el juicio subyaciente a esta proposición axiológica puede $a$ ) significar que Juan va a la escuela, en cuyo caso mi proposición simplemente confirma lo que pasa, y es, por lo tanto, verdadera (semejante proposición de deber puede llamarse analítica); o bien, $b$ ) el juicio subyacente puede ser problemático, no afirmando ni negando que Juan vaya a la escuela (en este caso el valor de verdad de la proposición de deber es hipotético y su valor de verdad no es fácil de determinar); finalmente $c$ ) puedo saber que Juan no va a la escuela (en este caso el juicio subyacente es negatorio). La proposición de deber es sintética, porque desea algo que es nuevo y su valor de verdad es también diferente. De esta manera, la relación que guarda el trasfondo de la realidad actual objetiva con la verdad o falsedad de las proposiciones lógicas, es la misma que guarda el trasfondo de la realidad actual subjetiva, expresada en una estructura de modalidades, con la verdad y falsedad de las proposiciones axiológicas. La estructura subjetiva del trasfondo del "debe" sistematiza una parte de lo que Stevenson llama sentido emotivo y una parte de lo que Leys llama deliberación. El sujeto axiológico, pues, provee a la proposición de verdad o falsedad empírica, la cópula axiológica la provee de verdad axiológica, y el predicado axiológico la provee de validez.

Puesto que una proposición axiológica puede ser axiológica de siete maneras distintas -o bien sus tres términos pueden ser axiológicos, o bien sólo dos, o sólo uno-, su verdad y su validez dependen de las distintas combinaciones de los términos y de sus estructuras subyacentes. El análisis de la ver-

teoría evita la falacia naturalista. El "bien", o cualquiera de sus definitorios, no puede a su vez ser sujeto del "bien". Esto se infiere asimismo de lo dicho antes sobre el sujeto axiológico: ha de ser empírico y no sistemático. 
dad y la validez de las proposiciones de valor es uno de los aspectos más fascinantes de la axiología. 63

5. Hasta aquí la respuesta a nuestra cuarta cuestión, relativa a la estructura y las categorías de una ciencia de valor. Vayamos ahora a la quinta cuestión y preguntémonos si este proyecto de una ciencia axiológica, $u$ otro cualquiera similar, puede funcionar eficazmente en las situaciones morales. A la primera inspección parecería que un esquema tan abstracto se encuentra tan lejos de la acción moral como lo está, por ejemplo, la fórmula einsteiniana $\mathrm{E}_{\mathrm{c}}=\mathrm{mc}^{2}$, de la bomba atómica. Empero, la comparación pone ya en claro el poder potencial del sistema. Una vez esté ahí no puede por menos de convertirse en guía del pensamiento moral y en instrumento para la ordenación de las situaciones morales. La ciencia que sería aplicada en las situaciones no sería axiología, ni siquiera axiología aplicada, esto es, ética, sino ética aplicada -aquí está la otra parte de lo que Leys llama deliberación. Es, por decirlo así, una aplicación de la axiología aplicada. La ética misma sería lo que Leys llama “algo así como una lista de fórmulas matemáticas", en la cual quedarían sistematizados los sistemas de las teorías éticas, desde Platón hasta Dewey. Esta sistematización de las teorías éticas es posible sólo por la axiología, que en este respecto funciona como meta-ética. Sólo mediante esta sistematización es posible que la ética realice el papel que Leys le asigna, a saber: el de aplicarse al juicio moral como la lógica se aplica al juicio lógico, y estar concentrada en "unas pocas ideas".

Así como fué necesario recorrer un largo camino para que las matemáticas llegaran a ser la guía de las manos hábiles de un mecánico, hay que recorrer también un largo camino hasta el momento en que la axiología pueda convertirse en guía para la capacidad del hombre de ordenar su propia situación vital. Pero este último proceso es tan inevitable como lo fué el primero. La erección de una sociedad moral debe derivar tan inevitable e irresistiblemente de la lógica inherente al nuevo sistema de la axiología como la construcción de la sociedad tecnológica fué secuencia inevitable e irresistible de la lógica inherente al sistema de las matemáticas. Todo lo que necesitamos son reglas de aplicación, por medio de las cuales la axiología se filtre con éxito hasta las situaciones concretas. La primera tarea, a este respecto, es la de aclarar las relaciones mutuas de las diversas ciencias morales y humanas. Hemos visto ya que la aplicación del bien intrínseco a las personas conduce a la ciencia de la ética. En general, las ciencias sociales y humanas surgen por la aplicación de las categorías de la axiología, especialmente las de valor extrínseco e intrínseco, a los diversos campos de la vida individual y social. La tercera categoría, el valor sistemático, se aplica automáticamente siempre

63 Para más detalles, véase "Value Propositions" del autor, en el volumen próximo a aparecer The Language of Value, ed. Ray Lepley. 
que se erige un sistema. Significa que los términos del sistema quedan, como tales, excluídos de la estimación, la cual se aplica sólo a las cosas empíricas.

Las categorías de la axiología son universalmente aplicables, pero trataremos de cuatro clases de aplicaciones: 1) a personas, 2) a grupos de personas, 3) a cosas, y 4) a grupos de cosas. Estas cuatro aplicaciones de las dos categorías arrojan ocho ciencias.

La aplicación del valor extrínseco a las personas individuales mostraría a cada persona como una clase de funciones. Esto nos daría la ciencia de la psicología. El valor extrínseco aplicado a grupos de personas mostraría a estos grupos como clases de funciones realizadas por personas, o bien a las personas como funciones dentro de los grupos sociales. Esta sería la ciencia de la sociología. El valor extrínseco aplicado a las cosas individuales mostraría cada cosa como una clase de funciones. Esto nos daría la ciencia de la tecnología. El valor extrínseco aplicado a grupos de cosas mostraría a éstas como funciones dentro de grupos de cosas similares. Esta estimación comparativa de las cosas como funciones, llamadas "bienes", es la ciencia de la economía.

El valor intrínseco aplicado a las personas individuales muestra el carácter único de cada persona y produce la ciencia de la ética. El valor intrínseco aplicado a grupos de personas mostraría el carácter único de estos grupos, el valor de sus símbolos e instituciones, y nos daría la ciencia politica. El valor intrínseco aplicado a cosas individuales consideraría las cosas como valores individuales, y nos llevaría a la estética. Y el valor intrínseco aplicado a grupos de cosas mostraría los valores únicos de tales grupos o configuraciones de cosas. Esto sería una ciencia de la civilización.

Todas estas ciencias tienen sus predicados específicos y estos predicados son los predicados axiológicos aplicados. Una vez que haya quedado claro a qué ciencia pertenece el predicado, cabe analizar confusiones como la que sc da entre "bien" moral y "bien" axiológico, o como el uso intercientífico de predicados tales como "bello" en la moralidad. "Bello" es el predicado de la estética. La estética surge de la aplicación del "bien" axiológico intrínseco a las cosas. "Bien" intrínseco significa realización del concepto descriptivo o Gestalt. Lo "bello" como "bien" estético -esto es, el bien intrínseco aplicado a las cosas- significa, pues, que una cosa realiza en plenitud su Gestalt -que tiene lo que se ha llamado "unidad orgánica", "unidad en la variedad", etcétera. Las relaciones formales del "bien" intrínseco aplicadas a una cosa dan significación exacta a todos estos términos. "Bello", entonces, es la aplicación estética del "bien" axiológico intrínseco, tal y como el "bien" moral es su aplicación ética. Hablar de un carácter bello, pues, es una mezcla de ética y estética que puede ahora analizarse en términos exactos. En tanto que "un buen carácter" se refiere a la correspondencia de la imagen que la persona se hace de sí misma con su propia realidad, un "carácter hermoso" se refiere al carácter como forma, a su Prägnanz, su acabado, su organización. Esto nos 
da nuevas posibilidades de interpretación de algunos de los problemas suscitados en la tercera Crítica de Kant.

La aplicación de la axiología a las situaciones reales mediante la ciencia axiológica aplicada es una vasta tarea para nuevas generaciones de profesionales de la axiología pura y aplicada, para nuevas generaciones de protesionales de las ciencias sociales y morales puras y aplicadas, y, finalmente, para los mecánicos y artesanos de estas situaciones sociales. De su trabajo combinado debe surgir el mundo del futuro. Esta no es una visión utópica, sino una simple previsión de las cosas que habrán de venir gracias al desarrollo de la filosofía moral. Tan seguramente como los logros de los filósofos. naturales, al analizar situaciones naturales en términos matemáticos, han conducido a la construcción de fábricas que producen cosas nuevas y nunca soñadas, las realizaciones de los filósofos morales, al analizar situaciones sociales en términos de teorías de valor, conducirán a la constitución de instituciones que crearán un nuevo tipo de hombre.

ROBERT S. HARTMAN

Ohio State University Estados Unidos.

(trad. Jorge Portilla) 